\title{
Short-Term Effects of Ozone on Mortality: Comparative Analysis of Urban and Suburban Zones in Madrid (Spain)
}

\author{
Estrella López ${ }^{1,3}$, Pedro Salvador ${ }^{2}$, Begoña Artiñano ${ }^{2}$, Saul García $^{3}$, Rosalía Fernández ${ }^{3}$ and Manuel Posada ${ }^{1}$ \\ 1. Institute of Rare Diseases Research, Instituto de Salud Carlos III \& Centre for Biomedical Network Research on Rare Diseases \\ (CIBERER), Avda. Monforte de Lemos, Madrid 5, 28029, Spain
}

2. Atmospheric Pollution Division, Centre for Energy, Environment and Technology Research (CIEMAT), Avenue Complutense, Madrid 40, 28040, Spain

3. Department of Atmospheric Pollution, National Centre of Environmental Health, Instituto de Salud Carlos III (ISCIII), road Majadahonda-Pozuelo km. 2.200, Majadahonda, Madrid 28220, Spain

\begin{abstract}
A large number of papers published in the last decades are related to the effect of ozone exposure on mortality worldwide. Several studies have been performed to investigate the effect of ozone on mortality in Madrid (Spain), but the findings of these local reports were focused only on the Madrid city. The association of daily concentrations of ozone with daily mortality was investigated using autoregressive Poisson regression models. This study explores the effects of ozone on all causes except accidents, cardiovascular and respiratory short-term mortality in two areas of the Madrid region: an urban area constituted by the Madrid municipality and an industrial sub-urban area surrounding the city. Using three years of daily data (2003-2005), it was analyzed the all-ages populations and the over-64 age groups. The average ozone concentrations over the study period were $54.07 \pm 27.17 \mu \mathrm{g} / \mathrm{m}^{3}$ in the Madrid municipality and $70.09 \pm 32.96 \mu \mathrm{g} / \mathrm{m}^{3}$ in the sub-urban municipalities surrounding the city. Our results in the all-ages group indicated that $0.69 \%$ of all causes except accidents, $1.15 \%$ of cardiovascular and $1.56 \%$ of respiratory daily deaths, respectively, could be attributed to exposure to ozone in the Madrid city, whereas $11.69 \%$ of daily respiratory deaths were attributable to ozone exposure in the Madrid sub-urban surroundings. Our results show a clear association between mortality and ozone exposure. The spatial heterogeneity of ozone effects on short-term mortality throughout the Madrid region may have implications for local environmental policies and also for social and health services planning.
\end{abstract}

Key words: Ozone, mortality, cardiovascular, respiratory, Madrid city, sub-urban areas.

\section{Introduction}

\subsection{Ozone Pollution}

Complex photochemical processes in the lower atmosphere, involving nitrogen oxides and volatile organic compounds as precursors, lead to ozone production. Road transport, power and heat generation are the main sectors that emit ozone precursors [1]. Ozone pollution is especially important in Mediterranean areas of Europe, where climatic conditions (high sunshine) and anthropogenic emissions favour the accumulation and transport of

Corresponding author: Estrella López, Ph.D., research fields: environmental health, rare diseases research, biochemistry, microbiology and pharmacy. highly polluted air masses [2, 3]. Experimental characterization and modelling of the dynamics and behaviour of photochemical pollution in the Madrid air basin have been carried out by Plaza et al., Martín et al. and Palacios et al. [4-8].

\subsection{Health Effects of Ambient Ozone}

This pollutant is a powerful oxidant, and, as such, it can react with a wide range of cellular components and biological materials [9], exerting a harmful action not only in humans, but also in animals and plants. In humans, short-term ozone exposure has been linked to adverse respiratory effects including impairment of lung function, increased airway reactivity, and increase in respiratory symptoms, especially in 
subjects with asthma and chronic obstructive pulmonary diseases [10-14]. More limited is the evidence on its association with cardiovascular events [14], although some effects of ozone on the cardiovascular system such as vasoconstriction, systemic arterial hypertension and arrhythmias, have been described [15]. Epidemiological time-series studies have revealed an association between ozone concentrations and daily mortality for respiratory as well as cardiovascular causes [10, 14, 16-18]. Based on these type of studies, the World Health Organization (WHO) estimated that the increase in the number of attributable deaths is $1-2 \%$ on days when the 8-hour mean ozone concentration reaches 100 $\mu \mathrm{g} / \mathrm{m}^{3}$ (current guideline value for ozone, established by WHO Air Quality Guidelines, global update 2005) over that when ozone levels are at a baseline level of $70 \mu \mathrm{g} / \mathrm{m}^{3}$ (the estimated background ozone level). However, considerable individual variation in response to ozone was described and it is possible that health effects might occur below the guideline level in some sensitive individuals [19]. Actually, the latest WHO review on the health effects of air pollution [20] concluded that there was new scientific information on the adverse health effects of ozone, observed at levels commonly present in Europe. To date, little work has been directed toward identifying which subpopulations are more susceptible to death due to the effects of ambient ozone [12, 17].

Recently, interest in epidemiological studies has grown in how socioeconomic status, individual characteristics (e.g., age, race and gender) or weather conditions modify associations of exposure to air pollution with mortality [17]. The physical environment in which people live retains great importance amongst the factors which interact to create and destroy health and wellbeing. It is a complex system of interactions between exposure to pollutants (for example, air pollution, noise, poor quality water, chemicals, etc.) and other environmental, economic, social and health aspects
[21]. This growing recognition of the complexity of interactions between environmental factors and their impacts on human health within a specific context calls for reaching the highest spatial resolution in the studies regarding the relationship between exposure to air pollutants and health data.

\section{Problem Formulation}

The Madrid Community is a region located in the centre of Spain, whose population is distributed unevenly among the city of Madrid and the outskirts. The main problems related to air pollution in the Madrid Community are concentrated in the central city and its suburbs with high density of populations and activities [22]. Although several studies have been developed to investigate ozone's effects on mortality in the Madrid municipality [23-25], studies addressing this pollutant's effects on health are practically non-existent in the sub-urban municipalities surrounding the central urban area, despite the fact that these are industrialized and polluted (mainly by particles and ozone) zones and also they have a high number of inhabitants. The aim of this study is to perform a spatial analysis, which explores the effects of ozone on all causes except accidents, cardiovascular and respiratory short-term mortality in two areas of the Madrid region: an urban area constituted by the Madrid municipality and an industrial sub-urban area surrounding the city. Using three years of daily data (2003-2005), it was analyzed the whole populations (all ages) and the over-64 age groups. This period corresponds to the study time established by the European project HEREPLUS [26], which aimed to evaluate the association between environmental air pollution and health, and to provide guidelines for the management of the urban environment.

\subsection{Study Area}

In 2001, the Madrid Community government established an environmental classification to fulfil the requirements of the 96/62/EC directive concerning the 

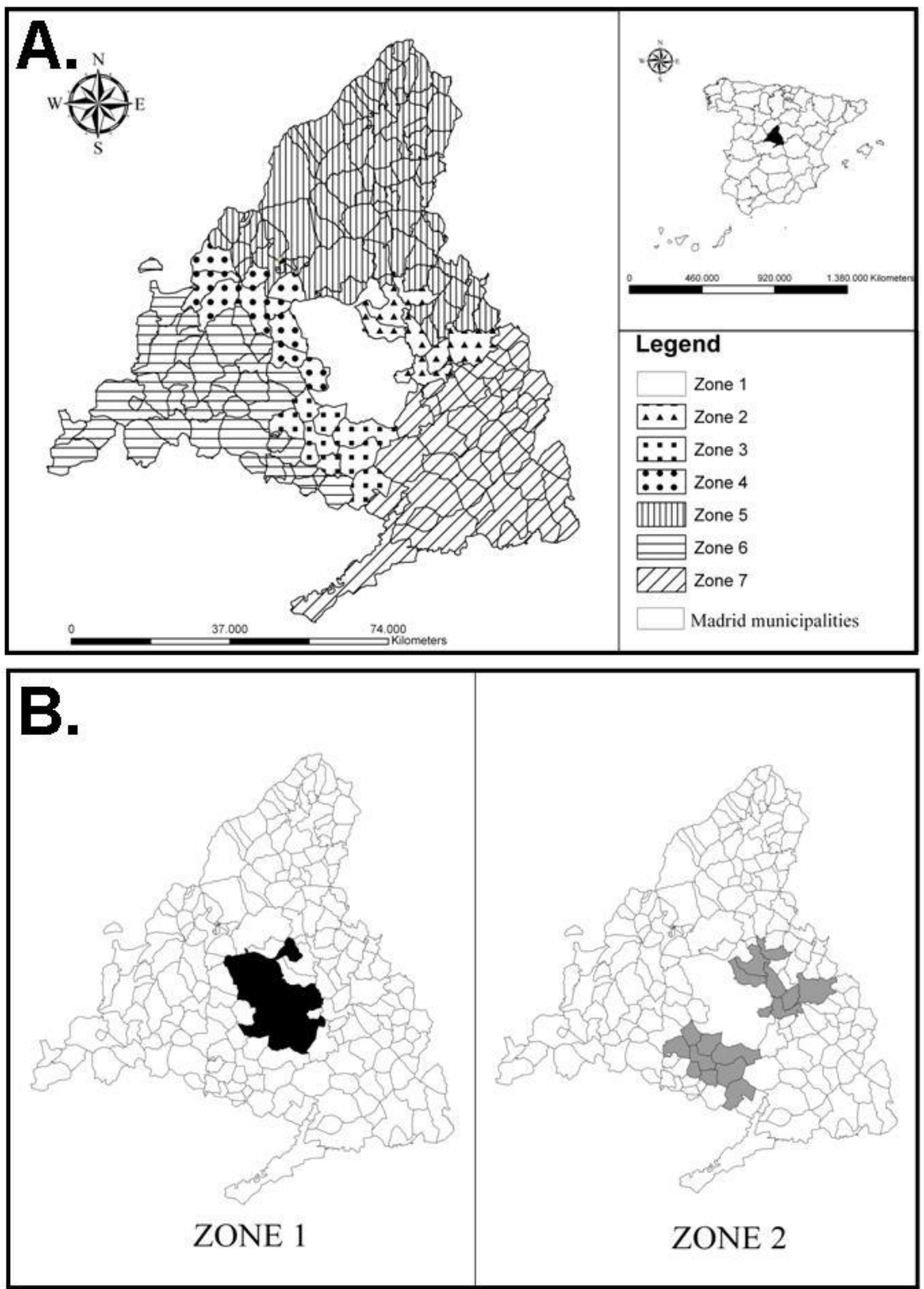

Fig. 1 (A) Environmental zoning of the Madrid region for air quality assessment (established by the Madrid Community government in 2001) and (B) Madrid zones considered in this study for the statistical association between the exposure to ozone and its effect on mortality.

air quality assessment in the European Member States territory. Following this classification, valid for the period 2001-2006, the Madrid Community was divided into seven homogeneous areas (Fig. 1A).

In this study, focused on urban environments, the three Madrid central zones (named 1, 2 and 3) were selected for research. The central urban area, constituted by the Madrid municipality ("zone 1") was a highly populated area and highly influenced by traffic emissions. North-eastern and southern zones surrounding the Madrid municipality (zones 2 and 3) were quite populated and characterized as those areas where industrial activity was the most intense. In addition, both zones showed similar environmental, socio-economic and demographic characteristics. Finally, zones 2 and 3 were merged into one unique zone named "zone 2" (Fig. 1B) to increase the population size and, in this way, the statistical power of the study. 
Exposure to pollutants was not assessed individually. For the assessment of population exposure, each inhabitant (corresponding to a mortality outcome) was assigned to an environmental area (zone 1 or zone 2), taking into account their residence place. We assumed that all the inhabitants living in the same Madrid zone were exposed to the same pollutants doses. The air pollutants concentration values assigned to a zone were obtained by calculating the daily average of the concentration values detected in all of the stations located in the same zone.

\subsection{Mortality Data}

The study population was composed by Madrid residents in zones 1 or 2, who died in Madrid for the period from 2003 to 2005 as consequence of all causes except accidents (ICD-10 codes A00-R99), cardiovascular events (ICD-10 codes I00-I99) or respiratory causes (ICD-10 codes J00-J99). For the sake of simplicity, all causes except accidents will be referred from now on simply as "all causes".

Validated and qualified data on mortality were provided by the Madrid Community Institute of Statistics.

\subsection{Environmental Data}

Chemical air pollutants and meteorological variables used in this study were: daily mean concentrations (expressed as micrograms per cubic meter, $\left.\mu \mathrm{g} / \mathrm{m}^{3}\right)$ of nitrogen dioxide $\left(\mathrm{NO}_{2}\right)$, sulphur dioxide $\left(\mathrm{SO}_{2}\right)$ and particulate matter with aerodynamic diameter $<10 \mu \mathrm{m}$ (PM10), daily maximum 8-hour mean ozone $\left(\mathrm{O}_{3}\right)$ concentrations (expressed as micrograms per cubic meter, $\mu \mathrm{g} / \mathrm{m}^{3}$ ) and daily mean values of temperature (expressed as degrees Celsius, ${ }^{\circ} \mathrm{C}$ ), atmospheric pressure (expressed as Hectopascals, $\mathrm{hPa}$ ) and relative humidity (expressed as percentage).

Environmental data were supplied by two different organizations: the Madrid Municipality authority and the Madrid Community government. The air quality network managed by the Madrid municipality consisted of 27 monitoring stations located in almost all the districts of the zone 1 . The regional network contributed with 9 stations distributed throughout the zone 2. Data on air pollutants and meteorological variables were obtained for the years 2003 to 2005 from those environmental stations located in zones 1 and 2. The network managers provided the data sets validated and excluding those periods when the automatic devices were damaged or being checked. Besides, the time series were checked again for this study to detect anomalies. Daily maximum 8-hour mean $\mathrm{O}_{3}$ concentrations were obtained from hourly data with a minimum data capture of $75 \%$, as required in the 2008/50/EC European directive [27].

\subsection{Other Data}

Other variables included in our study were:

- Pollen data, that consisted of daily mean concentrations of pollens (number of pollen grains per cubic meter, grains $/ \mathrm{m}^{3}$ ) having high allergenic potential: Cupressaceae, Olea europaea, Platanaceae and Poaceae pollen. Pollen data were collected by the Palynology Network of the Madrid Regional Health Authority. The regional network contributed with 2 stations distributed throughout the zone 1 and 5 stations in the zone 2. It was calculated the daily average of pollen concentration values coming from different stations in each zone.

- Influenza epidemic periods, expressed as number of weekly influenza cases in Madrid (data provided by the National Centre of Epidemiology).

- Saharan dust episodes, defined through a dichotomic variable equalling " 1 " in Saharan dust episodes and " 0 " in periods when there were no episodes. The occurrence of Saharan dust episodes over the study area, were documented on the basis of a meteorological analysis and information obtained from satellite imagery and numerical models as described by Salvador et al. [28]. The impact of the dust transported by the African air masses on levels of PM10 registered in the environmental stations was 
highly significant, giving rise to exceedances of the PM10 daily limit value $\left(50 \mu \mathrm{g} / \mathrm{m}^{3}\right)$ established by the European directive 2008/50/EC on air quality. On average during the 2001-2008 period, the annual number of PM10 daily limit value exceedances exclusively attributed to Saharan dust ranged from 14 to 16 at the Madrid municipality and regional environmental stations [28].

- Time-series autocorrelation, controlled through the introduction of 2 lags for the corresponding dependent variable.

- Sinusoidal terms (sines and cosines) to control for seasonality and dummy variables for each day of the week.

\subsection{Statistical Analysis}

The association of daily concentrations of ozone with daily mortality was investigated using autoregressive Poisson regression models. Daily mortality for cardiovascular, respiratory and all causes was considered as the dependent variables. The independent variables were the aforementioned ones in the sections "environmental data" and "other data".

It is broadly known the fact that the relationship between mortality and temperature is not linear, but quadratic. In order to consider this type of functional relationship, we created new variables (linear variables) for temperature following a similar methodology as described by Linares and Diaz [29]. The chosen threshold for setting the new temperature variables (hot branch and cold branch) was a mean temperature of $21^{\circ} \mathrm{C}$, which is the established value for the comfort temperature.

The choice of thresholds for air pollutants was based on reference levels established by the WHO or natural background levels. The selected threshold for PM10 was $50 \mu \mathrm{g} / \mathrm{m}^{3}$ (24-hour mean), the corresponding Air Quality Guideline established by the WHO [19]. Regarding ozone, the applied threshold value for studying the effect of this pollutant on mortality was $70 \mu \mathrm{g} / \mathrm{m}^{3}$ (daily maximum 8-hour mean), which is the established value for the background ozone level [19]. Scatter-plots diagrams were used to investigate the type of relationship between mortality and ozone concentrations. These diagrams showed that ozone levels fitted a quadratic curve when related to mortality and the minimum mortality occurred when ozone was at an approximate concentration of $70 \mu \mathrm{g} / \mathrm{m}^{3}$. This quadratic relationship led to ozone concentration to be divided into two branches, one corresponding to values above $70 \mu \mathrm{g} / \mathrm{m}^{3}$ (ascending branch) and another for lower values (descending branch).

Certain lags for the studied environmental variables were considered: 0-4 days for $\mathrm{PM}_{10}, \mathrm{NO}_{2}$ and $\mathrm{SO}_{2}$; 0-8 days for ozone; 0-14 days for temperature; 0-1 day for atmospheric pressure, 0-14 days for humidity and 0-8 days for pollen. The selected temporal interval for the time lags is extended enough to detect the related short-term health effects.

We started the Poisson regression analysis from an initial or saturated model (common for all of the zones, age strata and studied mortality outcomes) containing all the considered independent variables (including lagged variables). Variables were eliminated by a backward procedure, taking into account their respective levels of statistical significance. Only the variables that registered statistical significance in the final Poisson regression models ( $p$-value less than 0.05 ) were taken into account for building the final models. Relative risks (RRs) were obtained from the models estimates values and the corresponding attributable risks (ARs) among the exposed were calculated by using the formula: $A R=(R R-1) / R R$. For the sake of simplicity, AR among the exposed will be referred from now on simple as "AR".

Statistical analysis was performed using the SPSS version 18.0 for Windows software package (IBM-SPSS Ibérica, Madrid, España; www.spss.es).

\subsection{Validation of the Models}

The full final models obtained in our study for the 
period 2003-2005 were validated with the 2006 data in the same geographical zones. The objective of validation was to estimate the expected number of daily deaths by using some models obtained from data corresponding to other time period and to different population base. Thus, it was possible to compare two temporal series corresponding to the year 2006: first, the actual number of daily deaths and second, the estimated number of daily deaths (obtained by applying the final Poisson models for the period 2003-2005). Finally, a comparison between both temporal series in a daily basis was done. To quantify the correlation between both temporal series, Pearson coefficients were calculated.

In addition, for checking if our models were specific for each one of the studied geographical zones, the obtained mortality models corresponding to the zone 1 for the training dataset (2003-2005) were applied to the zone 2's 2006 data (and vice versa).

\section{Problem Solution}

\subsection{Demographic Characteristics of the Studied Zones}

The studied zones included 3,115,984 subjects residing in the zone 1 and 1,674,001 persons living in the zone 2 (data referred to the triennial average of the number of inhabitants for the period 2003-2005). The two areas of Madrid presented different demographic characteristics; thus, $8.72 \%$ of the population living in the zone 2 were over 64 years, while population from the zone 1 were quite older (18.99\% of persons living in the zone 1 were over 64 years).

\subsection{Air Pollution during the Study Period}

A descriptive analysis of the environmental variables for the period 2003-2005 in the two previously defined zones is shown in Table 1. Average ozone concentrations were $54.07 \pm 27.17$ $\mu \mathrm{g} / \mathrm{m}^{3}$ in the zone 1 and $70.09 \pm 32.96 \mu \mathrm{g} / \mathrm{m}^{3}$ in the zone 2 . The highest daily concentration recorded in the Madrid municipality was $137.60 \mu \mathrm{g} / \mathrm{m}^{3}$ and 163.20 $\mu \mathrm{g} / \mathrm{m}^{3}$ at the suburban municipalities surrounding the zone 1 . The number of exceedances over the WHO ozone guideline value was 48 in the zone 1 , in contrast with the 220 exceedances recorded in the zone 2.

Due to its photochemical nature, ozone annual levels followed a marked seasonal behaviour characterized by high concentrations during spring and, especially, summer and low concentrations during the coldest seasons (winter and autumn) (Fig. 2 ). The heat wave that took place in the summer of 2003 caused the highest values of both annual and summer ozone means during this year at almost all of the considered environmental stations; nevertheless, values in 2005 were close to them.

\subsection{All Causes, Cardiovascular and Respiratory} Mortality during the Study Period

A total of 78,855 deaths due to all causes were registered among zone 1 inhabitants for the period 2003-2005, with a mean of 71.95 deaths per day; the number of deaths due to cardiovascular causes was 24,499 (with a daily mean of 22.35) and due to respiratory illness was 11,907 (with a daily mean of 10.86). In the zone 2 , a total of 21,981 deaths were due to all causes (daily mean $=20.06$ ), 6,080 were related to cardiovascular events (daily mean $=5.55$ ) and 2,941 were due to respiratory causes (daily mean $=2.68$ ) (Table 2).

The temporal distribution of daily mortality registered a seasonal pattern, showing an increased number of deaths in winter/autumn compared to summer/spring. Mortality graphics revealed the existence of two important peaks corresponding to the heat wave occurred during the summer of 2003 and an influenza epidemic episode in the winter of 2005 (Fig. 3).

The age structure in zones 1 and 2 populations was different because population from zone 1 was quite older than population from zone 2 . It caused that crude mortality rates not adjusted by age strata were higher in the zone 1 than in the zone 2 (Table 3 ). 


\section{Suburban Zones in Madrid (Spain)}

Table 1 Statistics summary of air pollutants concentrations, weather conditions and pollen levels in Madrid zones 1 and 2 (2003-2005).

\begin{tabular}{|c|c|c|c|c|c|c|}
\hline Variable & $\begin{array}{l}\text { Daily mean } \\
\pm \text { SD }\end{array}$ & Daily median & $\begin{array}{l}\text { Minimum } \\
\text { daily value }\end{array}$ & $\begin{array}{l}\text { Maximum } \\
\text { daily value }\end{array}$ & 10th percentile & 90th percentile \\
\hline \multicolumn{7}{|l|}{$\mathrm{O}_{3}\left(\mu \mathrm{g} / \mathrm{m}^{3}\right)^{\mathrm{a}}$} \\
\hline Zone 1 & $54.07 \pm 27.17$ & 53.82 & 5.30 & 137.60 & 16.56 & 89.19 \\
\hline Zone 2 & $70.09 \pm 32.96$ & 68.30 & 6.50 & 163.20 & 25.40 & 114.82 \\
\hline \multicolumn{7}{|l|}{ PM10 $\left(\mu \mathrm{g} / \mathrm{m}^{3}\right)$} \\
\hline Zone 1 & $34.39 \pm 17.44$ & 31.65 & 8.30 & 152.30 & 15.22 & 56.38 \\
\hline Zone 2 & $41.26 \pm 20.51$ & 36.90 & 6.10 & 185.70 & 19.24 & 66.52 \\
\hline \multicolumn{7}{|l|}{$\mathrm{NO}_{2}\left(\mu \mathrm{g} / \mathrm{m}^{3}\right)$} \\
\hline Zone 1 & $60.34 \pm 17.80$ & 57.96 & 19.00 & 133.10 & 39.10 & 84.37 \\
\hline Zone 2 & $45.17 \pm 18.64$ & 42.60 & 8.30 & 121.10 & 23.67 & 71.29 \\
\hline \multicolumn{7}{|l|}{$\mathrm{SO}_{2}\left(\mu \mathrm{g} / \mathrm{m}^{3}\right)$} \\
\hline Zone 1 & $11.83 \pm 5.43$ & 9.92 & 4.70 & 36.10 & 7.08 & 20.07 \\
\hline Zone 2 & $6.52 \pm 3.82$ & 5.30 & 1.50 & 26.00 & 3.20 & 11.80 \\
\hline \multicolumn{7}{|c|}{ Mean temperature $\left({ }^{\circ} \mathrm{C}\right)$} \\
\hline Zone 1 & $16.81 \pm 7.84$ & 15.50 & 0.00 & 33.30 & 7.00 & 27.80 \\
\hline Zone 2 & $15.30 \pm 8.51$ & 13.80 & -2.70 & 32.60 & 4.90 & 27.24 \\
\hline \multicolumn{7}{|c|}{ Relative humidity (\%) } \\
\hline Zone 1 & $53.69 \pm 16.65$ & 50.50 & 24.40 & 92.70 & 33.70 & 78.40 \\
\hline Zone 2 & $55.66 \pm 21.44$ & 53.15 & 14.60 & 99.90 & 28.20 & 86.99 \\
\hline \multicolumn{7}{|c|}{ Atmospheric pressure $(\mathrm{hPa})$} \\
\hline Zone 1 & $928.67 \pm 5.87$ & 928.80 & 901.00 & 946.80 & 921.40 & 935.84 \\
\hline Zone 2 & $931.21 \pm 5.69$ & 931.20 & 905.00 & 948.20 & 924.47 & 938.20 \\
\hline \multicolumn{7}{|c|}{ Cupressaceae pollen (grains $/ \mathrm{m}^{3}$ ) } \\
\hline Zone 1 & $7.44 \pm 30.95$ & 1.00 & 0.00 & 442.00 & 0.00 & 14.00 \\
\hline Zone 2 & $13.41 \pm 56.02$ & 1.00 & 0.00 & $1,156.00$ & 0.00 & 23.00 \\
\hline \multicolumn{7}{|c|}{ Olea pollen $\left(\right.$ grains $\left./ \mathrm{m}^{3}\right)$} \\
\hline Zone 1 & $2.43 \pm 12.82$ & 0.00 & 0.00 & 240.00 & 0.00 & 4.00 \\
\hline Zone 2 & $3.77 \pm 16.89$ & 0.00 & 0.00 & 226.00 & 0.00 & 4.00 \\
\hline \multicolumn{7}{|c|}{ Platanus pollen $\left(\right.$ grains $/ \mathrm{m}^{3}$ ) } \\
\hline Zone 1 & $11.90 \pm 58.69$ & 0.00 & 0.00 & 803.00 & 0.00 & 9.00 \\
\hline Zone 2 & $12.24 \pm 79.89$ & 0.00 & 0.00 & $1,451.00$ & 0.00 & 6.40 \\
\hline \multicolumn{7}{|c|}{ Poaceae pollen $\left(\right.$ grains $/ \mathrm{m}^{3}$ ) } \\
\hline Zone 1 & $3.87 \pm 10.58$ & 1.00 & 0.00 & 116.00 & 0.00 & 8.00 \\
\hline Zone 2 & $6.72 \pm 21.73$ & 1.00 & 0.00 & 273.00 & 0.00 & 12.00 \\
\hline
\end{tabular}

Abbreviations: PM10, particulate matter $\leq 10 \mu \mathrm{m}$ in aerodynamic diameter.

${ }^{\mathrm{a}}$ ozone concentration units $=$ daily maximum 8 -hour mean. 

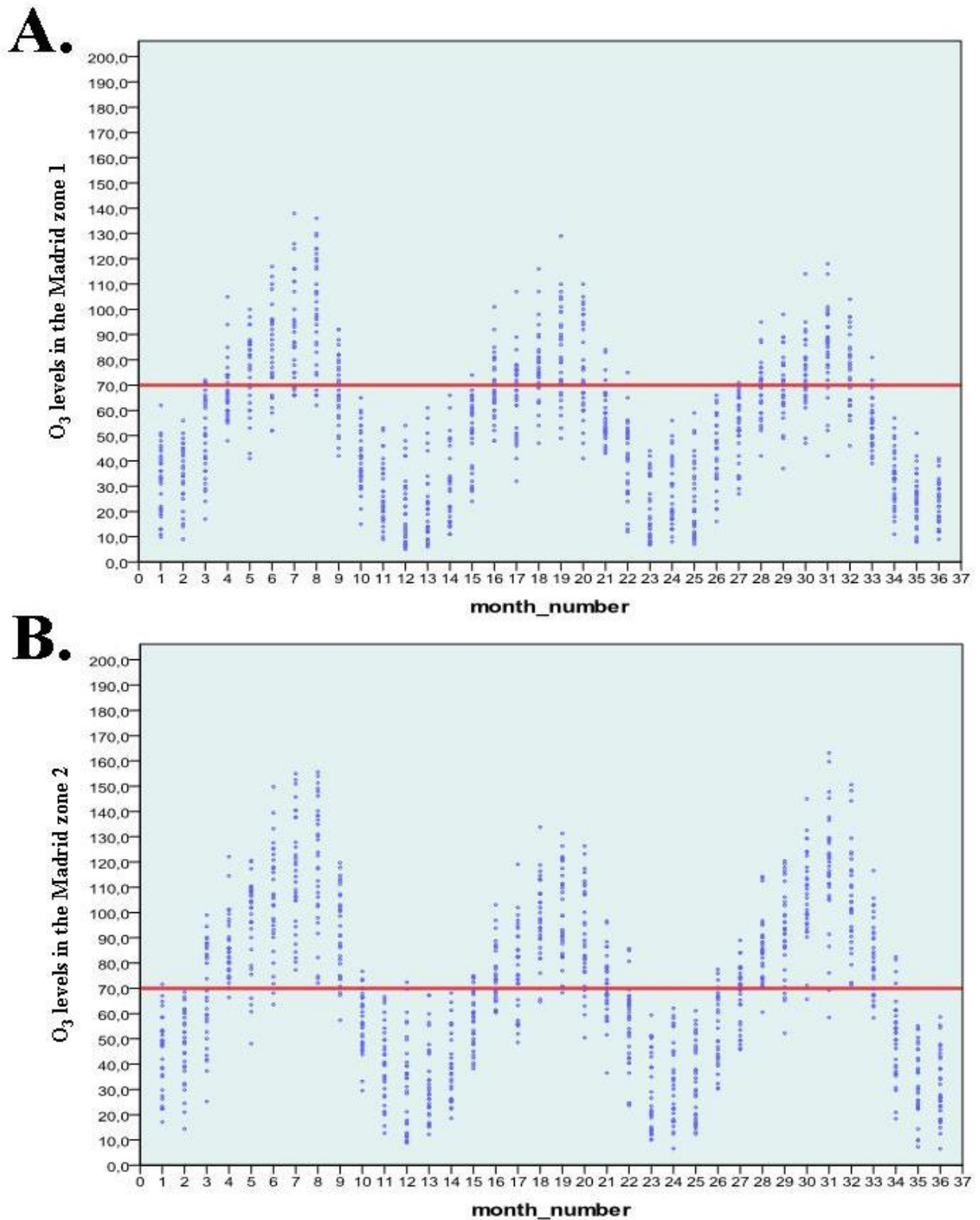

Fig. 2 Daily maximum 8-hour mean $\mathrm{O}_{3}$ values (expressed as $\mu \mathrm{g} / \mathrm{m}^{3}$ ) in the Madrid zones 1 (A) and 2 (B) by month number (2003-2005). Red lines represent the established $\mathrm{O}_{3}$ threshold (daily maximum 8-hour mean $=70 \mu \mathrm{g} / \mathrm{m}^{3}$ ) and daily ozone values are shown as blue circles.

Table 2 Statistics summary of all causes, cardiovascular and respiratory mortality in Madrid zones 1 and 2 (2003-2005).

\begin{tabular}{clllllll}
\hline Mortality outcome & $\begin{array}{l}\text { Sum of total } \\
\text { deaths }\end{array}$ & $\begin{array}{l}\text { Daily mean } \\
\pm \mathrm{SD}\end{array}$ & Daily median & $\begin{array}{l}\text { Minimum } \\
\text { daily value }\end{array}$ & $\begin{array}{l}\text { Maximum } \\
\text { daily value }\end{array}$ & $\begin{array}{l}\text { 10th } \\
\text { percentile }\end{array}$ & $\begin{array}{l}\text { 90th } \\
\text { percentile }\end{array}$ \\
\hline All causes mortality & & & & & & & \\
\hline Zone 1 & 78,855 & $71.95 \pm 12.66$ & 71.00 & 41.00 & 127.00 & 57.00 & 88.00 \\
Zone 2 & 21,981 & $20.06 \pm 4.98$ & 20.00 & 8.00 & 41.00 & 14.00 & 27.00 \\
\hline Cardiovascular mortality & & & & & & & 30.00 \\
\hline Zone 1 & 24,499 & $22.35 \pm 5.74$ & 22.00 & 9.00 & 49.00 & 15.00 & 9.00 \\
Zone 2 & 6,080 & $5.55 \pm 2.48$ & 5.00 & 0.00 & 16.00 & 3.00 & \\
\hline Respiratory mortality & & & & & & & \\
\hline Zone 1 & 11,907 & $10.86 \pm 4.85$ & 10.00 & 1.00 & 35.00 & 6.00 & 17.00 \\
Zone 2 & 2,941 & $2.68 \pm 1.81$ & 2.00 & 0.00 & 12.00 & 1.00 & 5.00 \\
\hline
\end{tabular}




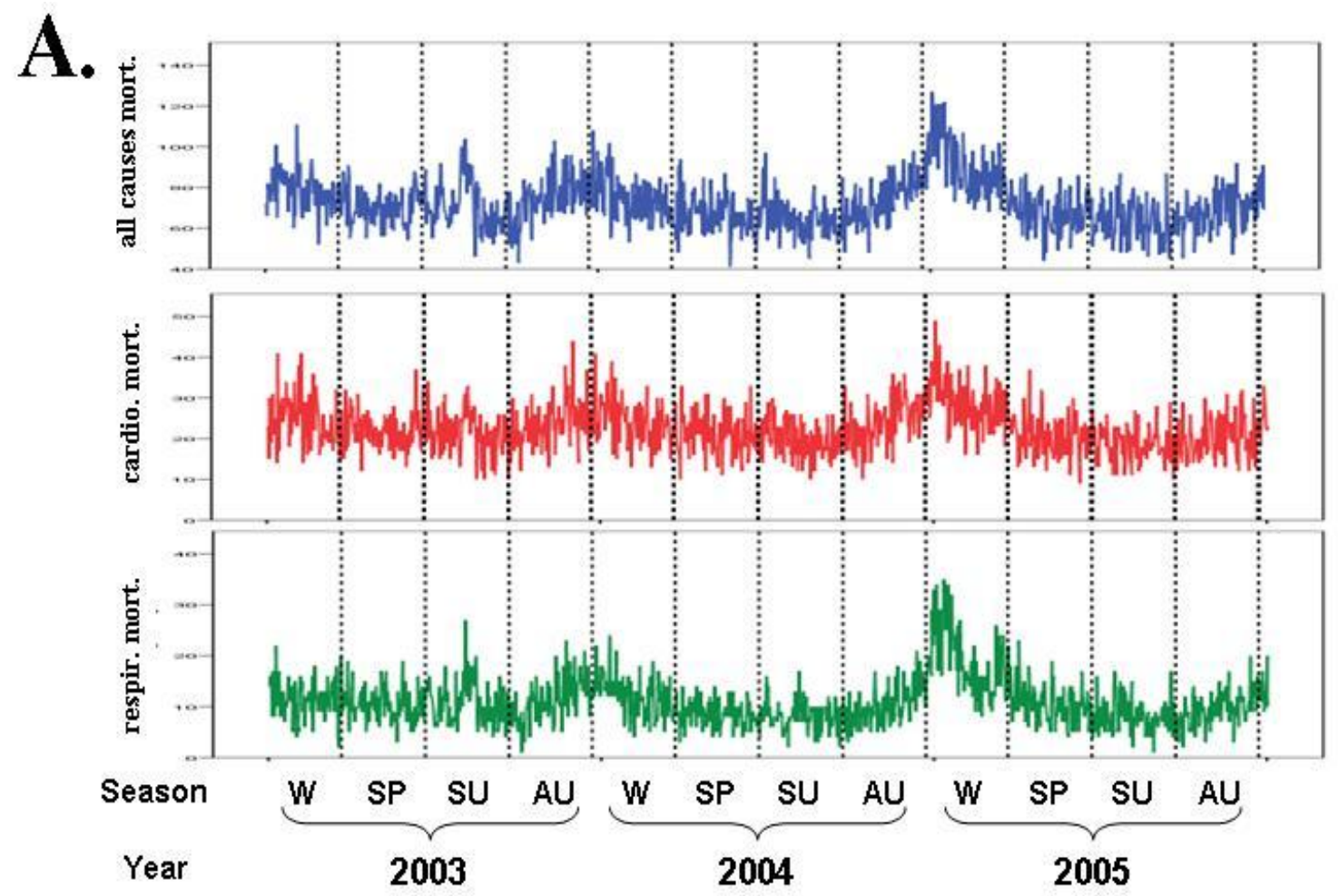

B.
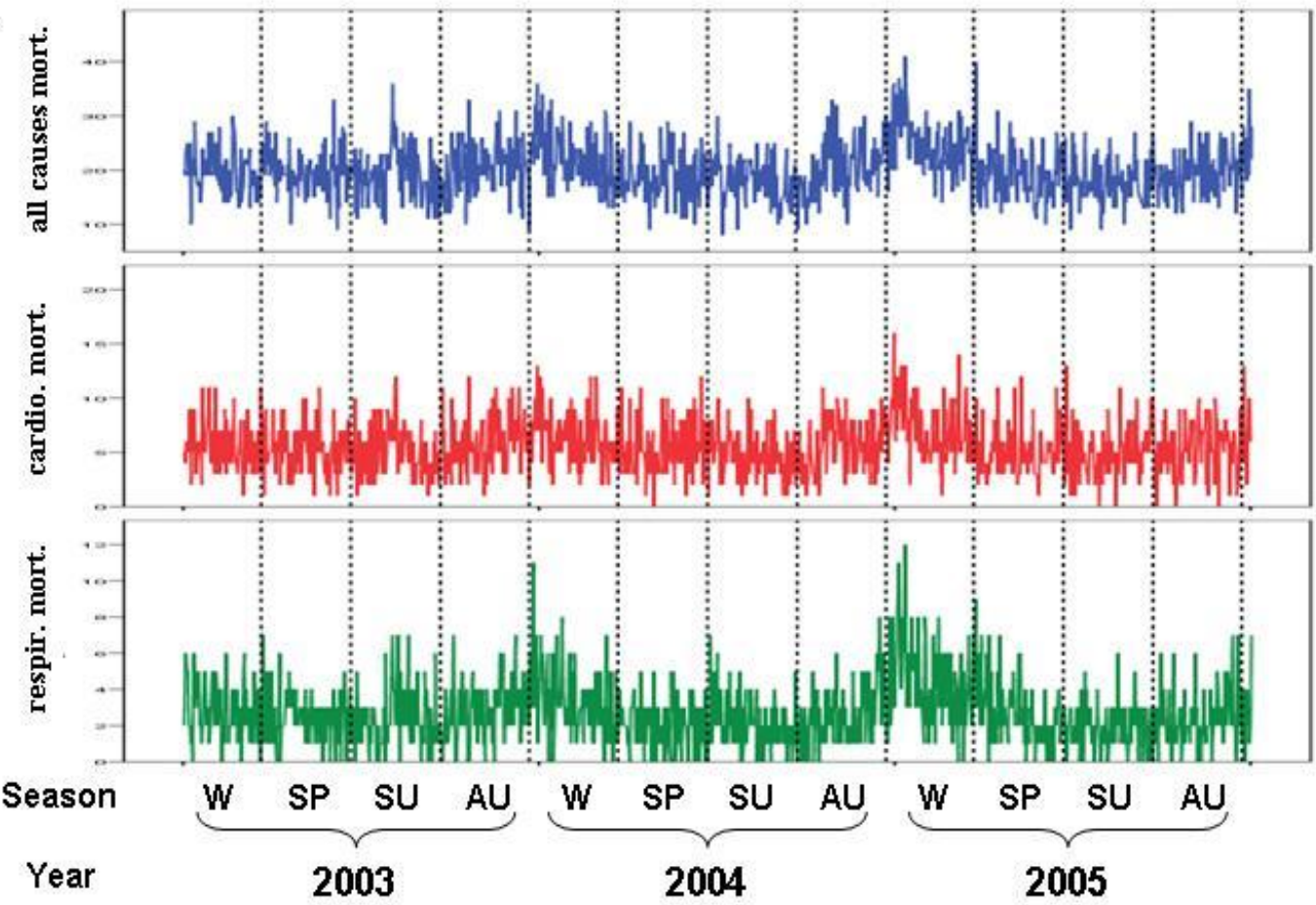

Fig. 3 Temporal distribution of all causes (blue lines), cardiovascular (red lines) and respiratory (green lines) mortality in the Madrid zones 1 (A) and 2 (B) for the study period (2003-2005).

Source: Vertical discontinuous lines delimit the four seasons of each year.

Abbreviations: all causes mort., number of daily deaths due to all causes; cardio. mort., number of daily deaths due to cardiovascular causes; respir. mort., number of daily deaths due to respiratory causes; W, winter; SP, spring; SU, summer; AU, autumn. 
Table 3 Crude all causes mortality rates by age and gender strata/1,000 inhabitants in Madrid zones 1 and 2 (2003-2005).

\begin{tabular}{lllllllll}
\hline & \multicolumn{9}{c}{ All causes mortality } \\
\cline { 2 - 10 } & Age $<15$ & Age 15-64 & Age > 64 & All ages & Age < 15 & Age 15-64 & Age > 64 & All ages \\
\hline Male & 0.826 & 2.439 & 44.821 & 8.878 & 0.562 & 1.992 & 41.905 & 4.797 \\
Female & 0.693 & 1.129 & 32.949 & 8.046 & 0.522 & 0.869 & 32.684 & 3.960 \\
Both & 0.762 & 1.763 & 37.554 & 8.436 & 0.543 & 1.435 & 36.680 & 4.378 \\
\hline
\end{tabular}

\subsection{Effects of Ozone on Mortality}

In the zone 1 , a $10 \mu \mathrm{g} / \mathrm{m}^{3}$ increment in the ozone levels over a threshold of $70 \mu \mathrm{g} / \mathrm{m}^{3}$ raised up the risk for all causes of death, with a RR of 1.014 (95\% CI $1.005,1.022)$ for all ages population and $1.022(95 \%$ CI $0.994,1.052$ ) for the over-64 age group (Table 4). The corresponding RRs values among the whole population for cardiovascular and respiratory mortality were 1.023 (95\% CI 1.008, 1.039) and 1.032 (95\% CI 1.007, 1.057), respectively. Among people aged over 64 years, these values were 1.026 (95\% CI $1.011,1.042)$ for cardiovascular mortality and 1.028 (95\% CI 1.003, 1.054) for respiratory mortality. However, in the zone 2, exposure to ozone was not associated with the overall risk of death, but it was correlated with an increase in the risk of death from cardiovascular causes in the over-64 age group,
$\mathrm{RR}=1.024(95 \% \mathrm{CI} 1.004,1.046)$ and from respiratory diseases in both all ages population, $\mathrm{RR}=$ 1.084 (95\% CI 1.007, 1.057) and the over-64 age group, $\mathrm{RR}=1.075$ (95\% CI 1.043, 1.107). An overview of these results indicated that ozone had the highest impact on respiratory mortality. These estimations revealed that $1.56 \%$ and $11.69 \%$ of daily deaths due to respiratory diseases could be attributed to exposure to ozone in the zone 1 and zone 2, respectively.

\subsection{Validation of the Statistical Models}

Regarding the validation of the obtained statistical models, the correlation between the time series constituted by the actual number of daily deaths and the estimated number of daily deaths was statistically significant ( $p$-values lower than 0.05) in both zones for all of the studied mortality outcomes (Table 5).

Table 4 Ozone-related relative and attributable mortality risks ${ }^{\mathrm{a}}$ in the Madrid zones 1 and 2 among all ages population and the over 64 age group (2003-2005).

\begin{tabular}{|c|c|c|c|}
\hline Zone \& age group & All causes mortality & Cardiovascular mortality & Respiratory mortality \\
\hline \multicolumn{4}{|l|}{ Zone 1} \\
\hline \multicolumn{4}{|l|}{ All ages } \\
\hline $\mathrm{RR}^{\operatorname{lagx}}(95 \% \mathrm{CI})$ & $1.014^{\operatorname{lgg} 6}(1.005,1.022)$ & $1.023^{\operatorname{lag} 6}(1.008,1.039)$ & $1.032^{\operatorname{lag} 5}(1.007,1.057)$ \\
\hline $\operatorname{AR}(\%)$ & $0.69 \%$ & $1.15 \%$ & $1.56 \%$ \\
\hline \multicolumn{4}{|l|}{$>64$ years } \\
\hline $\mathrm{RR}^{\operatorname{lag} x}(95 \% \mathrm{CI})$ & $1.022^{\operatorname{lag} 3 \& 6 \& 8}(0.994,1.052)$ & $1.026^{\operatorname{lag} 6}(1.011,1.042)$ & $1.028^{\operatorname{lag} 5}(1.003,1.054)$ \\
\hline $\mathrm{AR}(\%)$ & $1.10 \%$ & $1.30 \%$ & $1.40 \%$ \\
\hline \multicolumn{4}{|l|}{ Zone 2} \\
\hline \multicolumn{4}{|l|}{ All ages } \\
\hline $\mathrm{RR}^{\operatorname{lag} x}(95 \% \mathrm{CI})$ & $1.004(0.864,1.165)$ & $1.005(0.759,1.330)$ & $1.084^{\operatorname{lag} 3 \& 5}(1.016,1.155)$ \\
\hline $\mathrm{AR}(\%)$ & - & - & $11.69 \%$ \\
\hline \multicolumn{4}{|l|}{$>64$ years } \\
\hline $\mathrm{RR}^{\operatorname{lag} x}(95 \% \mathrm{CI})$ & $1.002(0.841,1.192)$ & $1.024^{\operatorname{lag} 0}(1.004,1.046)$ & $1.075^{\operatorname{lag} 3}(1.043,1.107)$ \\
\hline $\mathrm{AR}(\%)$ & - & $3.33 \%$ & $10.33 \%$ \\
\hline
\end{tabular}

Abbreviations: Lagx, ozone value lagged " $\mathrm{x}$ " days regarding the mortality outcome.

${ }^{a} \mathrm{RR}$ was calculated separately in the two Madrid zones for a $10 \mu \mathrm{g} / \mathrm{m}^{3}$ rise in the $\mathrm{O}_{3}$ levels (daily maximum 8 -hour mean, $\mu \mathrm{g} / \mathrm{m}^{3}$ ) above a threshold of $70 \mu \mathrm{g} / \mathrm{m}^{3}$. Corresponding AR was expressed as percentages. 
Table 5 Statistics summary of the two temporal series, actual and expected number of daily deaths, corresponding to the year 2006.

\begin{tabular}{|c|c|c|c|c|c|c|}
\hline $\begin{array}{l}\text { Mortality outcome } \\
\& \text { type of data } \\
\text { (actual or expected) }\end{array}$ & $\begin{array}{l}\text { Daily mean } \\
\pm \mathrm{SD}\end{array}$ & $\begin{array}{l}\text { Minimum daily } \\
\text { value }\end{array}$ & $\begin{array}{l}\text { Maximum daily } \\
\text { value }\end{array}$ & Total number & $\%$ Deviance & $\begin{array}{l}\text { Pearson } \\
\text { coefficient }\end{array}$ \\
\hline \multicolumn{7}{|l|}{ All causes mortality } \\
\hline \multicolumn{7}{|l|}{ Zone 1} \\
\hline Actual data & $70.15 \pm 9.60$ & 41 & 98 & 25,604 & \multirow{2}{*}{$4.91 \%$} & \multirow{2}{*}{$0.479 * *$} \\
\hline Expected data & $68.39 \pm 6.02$ & 54.18 & 83.11 & $24,346.82$ & & \\
\hline \multicolumn{7}{|l|}{ Zone 2} \\
\hline Actual data & $20.15 \pm 4.65$ & 9 & 36 & 7,354 & \multirow{2}{*}{$5.87 \%$} & \multirow{2}{*}{$0.150 * *$} \\
\hline Expected data & $19.72 \pm 1.86$ & 12.79 & 29.03 & $6,922.40$ & & \\
\hline \multicolumn{7}{|c|}{ Cardiovascular mortality } \\
\hline \multicolumn{7}{|l|}{ Zone 1} \\
\hline Actual data & $21.23 \pm 5.10$ & 7 & 34 & 7,750 & \multirow{2}{*}{$1.26 \%$} & \multirow{2}{*}{$0.317 * *$} \\
\hline Expected data & $21.44 \pm 2.22$ & 12.26 & 26.78 & $7,652.58$ & & \\
\hline \multicolumn{7}{|l|}{ Zone 2} \\
\hline Actual data & $5.40 \pm 2.40$ & 0 & 13 & 1,972 & \multirow{2}{*}{$1.42 \%$} & \multirow{2}{*}{$0.217 * *$} \\
\hline Expected data & $5.37 \pm 0.53$ & 4.56 & 6.96 & $1,943.91$ & & \\
\hline \multicolumn{7}{|l|}{ Respiratory mortality } \\
\hline \multicolumn{7}{|l|}{ Zone 1} \\
\hline Actual data & $10.37 \pm 3.45$ & 2 & 20 & 3,786 & \multirow{2}{*}{$7.04 \%$} & \multirow{2}{*}{$0.330 * *$} \\
\hline Expected data & $10.03 \pm 1.78$ & 6.31 & 14.55 & $3,519.40$ & & \\
\hline \multicolumn{7}{|l|}{ Zone 2} \\
\hline Actual data & $2.68 \pm 1.73$ & 0 & 9 & 978 & \multirow{2}{*}{$7.94 \%$} & \multirow{2}{*}{$0.110^{*}$} \\
\hline Expected data & $2.55 \pm 0.75$ & 0.60 & 6.25 & 900.39 & & \\
\hline
\end{tabular}

$* *=p<0.01$ and $*=p<0.05$.

The Pearson coefficient, used to quantify the correlation between the actual and the estimated temporal series, ranged from 0.110 to 0.479 , depending on the mortality outcome and the zone. On the other hand, results obtained after applying models corresponding to the zone 1 for the 2003-2005 period to the 2006 dataset of the zone 2 and vice versa, indicated that deviance percentages increased from $4.91 \%, 1.26 \%$ and $7.04 \%$ to $65.84 \%, 75.25 \%$ and $79.09 \%$ for all causes, cardiovascular and respiratory mortality respectively in the zone 1 and from $5.87 \%$, $1.42 \%$ and $7.94 \%$ to $67.71 \%, 74.14 \%$ and $68.12 \%$ for all causes, cardiovascular and respiratory mortality respectively in the zone 2 .

\section{Conclusions}

\subsection{Exposure Levels of Ozone}

Seasonal behaviour of ozone concentrations is a result of complex photochemical processes in the lower atmosphere. Summer conditions favour the formation of ozone primarily because of increased ultraviolet radiation and temperature and low wind speeds, but also because of increased precursor emissions, including nitrogen oxides from soils and increased levels of volatile organic compounds of anthropogenic and biogenic origin [9]. It explains why the highest ozone levels occurred during summer and late spring. Our data indicated that in Madrid city, daily maximum 8-hour ozone mean ranged from 5.30 $\mu \mathrm{g} / \mathrm{m}^{3}$ to $137.60 \mu \mathrm{g} / \mathrm{m}^{3}$, with a daily mean of 54.07 $\mu \mathrm{g} / \mathrm{m}^{3}$, whereas in Madrid sub-urban municipalities, daily ozone concentration ranged from $6.50 \mu \mathrm{g} / \mathrm{m}^{3}$ to $163.20 \mu \mathrm{g} / \mathrm{m}^{3}$, with a daily mean of $70.09 \mu \mathrm{g} / \mathrm{m}^{3}$. Therefore, zone 1 presented, as expected, lower ozone levels than zone 2 . The lowest ozone concentrations were recorded at the central urban site with heavy road traffic, mainly due to the ozone depletion by the NO emitted from traffic exhausts [30]. In general, 
ozone levels remained below the standards proposed by both WHO Air Quality Guidelines [19] and the European Union legislation [27], especially in zone 1, where only $4.4 \%$ of the days the ozone concentration exceeded the guideline value established by WHO. In the zone 2 , this percentage was $20.2 \%$. This highlights the importance of considering the different zones characteristics, and especially for some pollutants such as ozone, a secondary pollutant that presents its highest concentrations several kilometres downwind of the main source area of their precursors $\left(\mathrm{NO}_{\mathrm{x}}\right.$ and VOCs). These precursors react to form ozone as the urban plume is being transported away from the Madrid city as a consequence of the thermally driven wind flows, induced in this case by the topography of the Madrid basin [4]. In this study, an ozone cut-off concentration of $70 \mu \mathrm{g} / \mathrm{m}^{3}$ was used, which allowed for detecting ozone effects on mortality at levels below the WHO 2005 and EU 2008 standards of 100 $\mu \mathrm{g} / \mathrm{m}^{3}$ and $120 \mu \mathrm{g} / \mathrm{m}^{3}$, respectively.

\subsection{Ozone Effects on Mortality in Two Different Areas of the Madrid Region}

Mortality risk estimations among the all ages population showed that ozone exposure was associated to the three studied mortality outcomes in the Madrid municipality. However, an increased risk was found for respiratory causes, but not for cardiovascular causes neither all causes in the Madrid zone 2. It is worth to highlight that people living in the zone with the lowest average level of ambient ozone were more susceptible to cardiovascular and all causes ozone-related mortality. A possible explanation for this finding could be based on the differences between demographic characteristics of zones 1 and 2 and on the fact that low concentrations of ozone has a particularly detrimental effect on vulnerable populations like the elderly group, as suggested by some studies [12, 31-33]. Thus, the fact that population over 64 years was much higher in the zone $1(18.99 \%)$ than in the zone $2(8.72 \%)$ could prompt ozone exposure increased risk of cardiovascular and all causes mortality in the zone 1 , but not in the zone 2 . Because of the older population has a larger baseline mortality rate than the general population, the same ozone levels for the older and the general population would lead to a larger number of extra deaths for the elderly one [34]. It might explain an increased risk of ozone-related cardiovascular mortality in the zone 2 among the over-64 age group, but not among the all ages population. On the other hand, we cannot refuse the idea that the lack of statistical power could be affecting to the aforementioned not significant mortality risk estimators in the zone 2. If the study covered a longer period of time, we probably would achieve statistically significant results in that zone. However, it is clear that the presence of significant results for the remaining estimator values discard a global problem regarding the statistical power of the study. Also, we do not consider that the modelling procedure influences the results, because: (1) the same saturated model at the starting point was used for both zones, both age strata and all the studied mortality outcomes, as it is mentioned in the Methods section, and (2) the method for modelling (backward procedure) and the criteria for dropping out variables were always the same.

Our results indicated that ozone had a higher impact on cause-specific mortality than on all causes mortality. Thus, in the zone 1 , attributable mortality risk corresponding to an increase of $10 \mu \mathrm{g} / \mathrm{m}^{3}$ in the ozone levels over a threshold of $70 \mu \mathrm{g} / \mathrm{m}^{3}$ nearly doubled in the case of cardiovascular mortality $(1.15 \%)$ and nearly tripled in the case of respiratory mortality $(1.56 \%)$ with regard to all causes mortality AR $(0.69 \%)$. Our finding that ozone levels are associated with stronger mortality effects from respiratory than cardiovascular diseases is consistent with several prior studies in European [10, 18] and American cities [17, 31], but in contrast with other reporting greater cardiovascular than respiratory mortality due to ozone effects $[16,33,35,36]$. This variability of results may 
reflect different ozone-mortality relationships in the different cities or studies. However, it is necessary to highlight on this point that ozone effect estimates may be heterogeneous because of many other factors, including differences in: (1) the studied time periods and/or age groups; (2) the number and characteristics of the variables included in the models; (3) the modelling assumptions, etc. Thus, the fact of our results indicated markedly higher RRs than the described ones in the HRAPIE project [20], based on data from 32 European cities included in the APHENA study [36], could be due to the differences in the methodological approaches: (1) the differences in the chosen lag intervals for the effect of ozone on mortality throughout the different studies could affect the magnitude of the risk coefficients; (2) on the other hand, it should be noted that the coefficients in the APHENA study [36] were based on the whole range of observed ozone concentrations, including levels below $70 \mu \mathrm{g} / \mathrm{m}^{3}$ (daily maximum 8-hour mean). No assumption of "no effect" of the lower levels of ozone was thus made in the impact calculations. However, the HRAPIE experts [20] recommended a cut-off concentration of $35 \mathrm{ppb}\left(70 \mu \mathrm{g} / \mathrm{m}^{3}\right)$ to reflect greater confidence in the significant relationship above 35 ppb. In our study, the applied threshold value for studying the effect of ozone on mortality was 70 $\mu \mathrm{g} / \mathrm{m}^{3}$ too. This methodological difference between the APHENA study [36] and our study could influence in the magnitude of the risk coefficients obtained in both studies. Risk estimates obtained in our study for the zone 1 could be compared to that obtained in other studies conducted in the Madrid municipality [23-25], but the methodological differences among them, as well as the differences in the studied time periods [23, 25] or ages groups [24], make this comparison difficult.

Our results suggest that exposure to low ozone concentrations might induce cardiovascular effects, which would be especially outstanding in vulnerable sub-groups like the elderly one; however, ozone-induced respiratory effects could affect to the entire population, being greater in the zones with the highest ozone levels. A similar hypothesis was proposed by Medina-Ramón and Schwartz [12]. Other explanations to this spatial trend could be the special characteristics of these zones, such as the presence of concomitant pollutants, other environmental conditions, socio-economic factors, etc. For example, zone 2 is the Madrid area where industrial activity is more extended [37] and the major presence of industries may be influencing on risk: the emission of a variety of pollutants from those industries could affect the respiratory health status of zone 2 inhabitants, making them more susceptible to ozone harmful effects. Socio-economic factors may be also playing a role, although this is only a hypothesis. Unfortunately, socioeconomic data were not available for us because Spanish Data Protection Law does not allow the usage of this type of personal data. To date, little research has been conducted to assess differences in socio-economic status susceptibility to ambient ozone and most of these studies have failed to demonstrate a detrimental significant effect of a low socio-economic status or a low educational attainment on ozone-related mortality [12, 17, 32, 35]. In addition, chronic health conditions of the inhabitants were not examined in our study and some of them may also confer susceptibility to ozone effects [12], such as underlying chronic heart and lung diseases [34]. Therefore, differences on the number of persons with certain chronic diseases living in the zones 1 and 2 may influence risk estimates.

\subsection{Validation of the Obtained Models}

The importance of this study lies in the fact that it has allowed the development of models capable of quantifying the association between ozone and mortality in two different areas of the Madrid region, considering the different characteristics of each one of them. Due to the limitations inherent to these types of analysis, a validation process was performed. This 
process would be useful to account for uncertainty due to potential confounding factors (for example measurement errors and missing data) and to know how good these models were to predict the number of deaths occurring in the studied Madrid areas during another period of time different to the considered one in the present study. 2006 was the year selected to this validation procedure. Results of the verification process on the daily values showed a good agreement with the actual data both in terms of average mortality cases and of total number over the verification period, confirmed by the deviance percentages, which assumed values ranging between $1.26 \%$ and $7.94 \%$. Models developed for Madrid zone 1 were capable of predicting $95.1 \%, 98.7 \%$ and $93.0 \%$ of the all causes, cardiovascular and respiratory deaths for the 2006 year, respectively, whereas in the case of the Madrid zone 2, models were capable of predicting $94.1 \%, 98.6 \%$ and $92.1 \%$ of the deaths for the 2006 year due to all causes, cardiovascular and respiratory causes, respectively. Therefore, models developed for cardiovascular mortality showed the best fitting with the actual data in terms of deviance. Mortality estimations for the year 2006 were lower than the actual number of deaths; thus, this modelling approach may underestimate the actual risk for mortality. On the other hand, it is interesting to observe the narrower range of the predicted cases respected to the actual ones. This suggested that some other external confounding factors which could drive the number of deaths to reach some peak values (either as minima or maxima) were not taken into account in the analysis carried out. In addition, results obtained after applying models corresponding to the zone 1 for the 2003-2005 period to the 2006 dataset of the zone 2 and vice versa, showed a great increase in size of deviance percentages regarding mortality actual data, confirming the very high level of geographical accuracy of our models.

\subsection{Limitations of the Study}

- Health outcomes: Mortality endpoints studied in this article are grouped outcomes, including the whole group of respiratory diseases (ICD-10 codes J00 to J99) and the entire cardiovascular diseases (ICD-10 codes I00 to I99) group. Statistical studies related to more specific respiratory and cardiovascular outcomes such as infarction, asthma, bronchitis, lung cancer, etc., might allow a more precise RR estimation (if the statistical power of the study was high enough).

- Vulnerable groups: Risk estimations have been carried out both in the all-ages population and the elderly population. However, the study of the effect of ozone on other vulnerable groups like children or patients with pre-existing diseases would be useful for a more precise RR estimation (if the statistical power of the study was high enough).

- For the assessment of population exposure, a combination of the spatial distribution of both air quality and population density was required. In Madrid, the residence place of each inhabitant was linked to an environmental area. However, it is important to take into account that the actual individual exposure to ambient air pollutants cannot directly be derived from their residence place due to people's mobility through different areas of the city and to the activity patterns of the exposed population (zoning misclassification). This could have introduced a non-differential classification bias in the exposure and it might have derived in the reduction of the estimated RR value.

- As it is very well known, the estimate risks for mortality are affected by certain variables, which could act as either effect modifiers or confounding variables of the association between air pollution and health outcomes. Although the statistical analyses have been controlled for most major confounders, some of them (for example, noise levels, indoor air pollution, PM2.5, ultrafine particles, VOCs, PAHs, etc.) have not been included in the statistical studies due to a lack of available data.

- Multicollinearity issues: Poisson regression models with a set of highly correlated independent 
variables imply the existence of multicollinearity limitations.

- Time series length and population size: Studies based on data from multiple cities and/or long time periods (for example, the APHENA study [36]) have higher power and precision than studies based on data from only one city and/or short time periods.

\subsection{Final Conclusions}

In conclusion, results obtained in this work show a clear association between mortality and ozone exposure. However, the relationship between ozone and mortality was qualitatively and quantitatively different depending on the studied Madrid zone, and our models showed a very high level of geographical accuracy. Therefore, our results suggest that physical environment where people live (understood as a complex system of interactions with environmental, demographic, socio-economic and health factors) may modify the health effects of ozone on the population. These findings may have implications not only for local environmental policies but also for social and health services planning, taking into account the spatial heterogeneity of ozone effects on short-term mortality throughout the different areas of the Madrid region. Of course, the existence of some limitations inherent to this type of ecological studies has to be considered for any meaningful interpretation of the magnitude of the obtained RR values.

\section{Conflicts of Interest}

The authors declare they have no actual or potential competing financial interests.

No ethical conflicts exist in relation to this study because all the data involving human subjects are anonymous.

\section{Acknowledgments}

This research was funded by the European Commission FP7-ENV project "Health Risk from Environmental Pollution Levels in Urban Systems
(HEREPLUS)", contract 212854.

We wish give our thanks to the following contributors: the Madrid Community Institute of Statistics for supplying the mortality data; the Madrid Municipality authority and the Madrid Community government for providing the environmental data; the Palynology Network of the Madrid Regional Health Authority for supplying the pollen data and, the National Centre of Epidemiology for providing the influenza data. In addition, we also wish to give our special thanks to Julio Díaz and Cristina Linares for their support in the statistical analysis.

\section{References}

[1] EEA (European Environment Agency). 2012. Air Pollution by Ozone across Europe during Summer 2011. Overview of Exceedances of EC Ozone Threshold Values for April-September 2011, EEA Technical Report 1/2012, Copenhagen: European Environment Agency.

[2] Millán, M., Salvador, R., Mantilla, E., and Artíñano, B. 1996. "Meteorology and Photochemical Air Pollution in Southern Europe: Experimental Results from EC Research Projects." Atmos Environ 30 (12): 1909-24.

[3] Millán, M., Salvador, R., Mantilla, E., and Kallos, G. 1997. "Photo-oxidant Dynamics in the Mediterranean Basin in Summer: Results from European Research Projects." J Geophys Res 102 (D7): 8811-23.

[4] Plaza, J., Pujadas, M., and Artíñano, B. 1997. "Formation and Transport of the Madrid Ozone Plume." J Air Waste Manage Assoc. 47: 766-74.

[5] Martín, F., Palacios, M., and Crespí, S. N. 2001. "Simulations of Mesoscale Circulations in the Center of the Iberian Peninsula for Thermal Low Pressure Conditions. Part II: Air-Parcel Transport Patterns." J Appl Meteor 40 (5): 905-14.

[6] Palacios, M., Kirchner, F., Martilli, A., Clappier, A., Martín, F., and Rodriguez, M. E. 2002. "Summer Ozone Episodes in the Greater Madrid Area: Analysis of the Ozone Response to Abatement Strategies by Modelling." Atmos Environ 36 (a): 5323-33.

[7] Palacios, M., Martilli, A., Kirchner, F., Clappier, A., Martín, F., Rodriguez, M. E. 2002. "Photochemical Modelling of Summer Ozone Episodes in the Greater Madrid Area.” Int J Environ Pollut. 18 (3b): 243-59.

[8] Palacios, M., Martín, F., and Aceña, B. 2005. "Estimate of Potentially High Ozone Concentration Areas in the Centre of the Iberian Peninsula." Int J Environ Pollut. 24 (1-4): 260-71. 
[9] WHO (World Health Organization). 2000. Air Quality Guidelines for Europe. 2nd edition. WHO Regional Publications, European Series, No. 91, Copenhagen, World Health Organization Regional Office for Europe.

[10] Gryparis, A., Forsberg, B., Katsouyanni, K., Analitis, A., Touloumi, G., and Schwartz, J., et al. 2004. "Acute Effects of Ozone on Mortality from the "Air Pollution and Health: A European Approach' Project.” Am J Respir Crit Care Med. 170 (10): 1080-7.

[11] Levy, J. I., Chemerynski, S. M., and Sarnat, J. A. 2005. "Ozone Exposure and Mortality: An Empiric Bayes Metaregression Analysis.” Epidemiology 16 (4): 458-68.

[12] Medina-Ramón, M., and Schwartz, J. 2008. "Who Is More Vulnerable to Die from Ozone Air Pollution?" Epidemiology 19 (5): 672-9.

[13] Mudway, I. S., and Kelly, F. J. 2004. "An Investigation of Inhaled Ozone Dose and the Magnitude of Airway Inflammation in Healthy Adults." Am J Respir Crit Care Med. 169 (10): 1089-95.

[14] Stafoggia, M., Forastiere, F., Faustini, A., Biggeri, A., Bisanti, L., and Cadum, E., et al. 2010. "Susceptibility Factors to Ozone-Related Mortality: A Population-Based Case-Crossover Analysis." Am J Respir Crit Care Med. 182 (3): 376384.

[15] Srebot, V., Gianicolo, E. A., Rainaldi, G., Trivella, M. G., and Sicari, R. 2009. "Ozone and Cardiovascular Injury." Cardiovasc Ultrasound 7: 30.

[16] Bell, M. L., Dominici, F., and Samet, J. M. 2005. “A Meta-Analysis of Time-Series Studies of Ozone and Mortality with Comparison to the National Morbidity, Mortality, and Air Pollution Study." Epidemiology 16 (4): 436-45.

[17] Ren, C., Melly, S., and Schwartz, J. 2010. "Modifiers of Short-Term Effects of Ozone on Mortality in Eastern Massachusetts: A Case-Crossover Analysis at Individual Level." Environ Health 9: 3.

[18] Samoli, E., Zanobetti, A., Schwartz, J., Atkinson, R., LeTertre, A., and Schindler, C., et al. 2009. "The Temporal Pattern of Mortality Responses to Ambient Ozone in the APHEA Project." Epidemiol Community Health 63 (12): 960-6.

[19] WHO (World Health Organization). 2017. Air Quality Guidelines for Particulate Matter, Ozone, Nitrogen Dioxide and Sulfur Dioxide-Global Update 2005. http://whqlibdoc.who.int/hq/2006/WHO_SDE_PHE_OE H_06.02_eng.pdf, Accessed May 31.

[20] WHO (World Health Organization). 2013. "Health Risks of Air Pollution in Europe-HRAPIE Project. Recommendations for Concentration-Response Functions for Cost-Benefit Analysis of Particulate Matter, Ozone and Nitrogen Dioxide." Copenhagen, World Health Organization Regional Office for Europe.
[21] Morris, G. P. 2010. "Ecological Public Health and Climate Change Policy." Perspect Public Health 130 (1): $34-40$.

[22] Monzón, A., and Guerrero, M. J. 2004. "Valuation of Social and Health Effects of Transport-related Air Pollution in Madrid (Spain)." Sci Total Environ 334-5: 427-34.

[23] Galán, L. I., Aránguez, R. E., Gandarillas, G. A., Ordóñez, I. J. M., and Aragonés, S. N. 1999. "Estudio Multicéntrico Español Sobre la Relación Entre la Contaminación Atmosférica y la Mortalidad (in Spanish)." Rev Esp Salud Publica 73 (2): 243-52.

[24] Jiménez, E., Linares, C., Rodríguez, L. F., Bleda, M. J., and Díaz, J. 2009. "Short-Term Impact of Particulate Matter (PM2.5) on Daily Mortality among the over-75 Age Group in Madrid (Spain).” Sci Total Environ 407 (21): 5486-92.

[25] Saez, M., Ballester, F., Barceló, M. A., Pérez-Hoyos, S., Bellido, J., and Tenías, J. M., et al. 2002. "A Combined Analysis of the Short-term Effects of Photochemical Air Pollutants on Mortality within the EMECAM Project." Environ Health Perspect 110 (3): 221-8.

[26] Mannocci, A., Salvatori, E., Saulle, R., Incerti, G., Boccia, A., and Manes, F., et al. 2014. "Health Risks Associated with Urban Environmental Pollution in Europe: Results of the HEREPLUS Multicentre Study in Rome (Italy)." Ig Sanita Pubbl. 70 (5): 463-72.

[27] EU (European Union). 2008. "Directive 2008/50/EC of the European Parliament and of the Council of 21 May 2008 on Ambient Air Quality and Cleaner Air for Europe."

[28] Salvador, P., Artiñano, B., Molero, F., Viana, M., Pey, J., and Alastuey, A., et al. 2013. "African Dust Contribution to Ambient Aerosol Levels across Central Spain: Characterization of Long-Range Transport Episodes of Desert Dust." Atmos Res. 127: 117-29.

[29] Linares, C., and Diaz, J. 2010. "Short-term Effect of $\operatorname{PM}(2.5)$ on Daily Hospital Admissions in Madrid (2003-2005)." Int J Environ Health Res. 20 (2): 129-40.

[30] Brunekreef, B., and Holgate, S. T. 2002. "Air Pollution and Health." Lancet 360 (9341): 1233-42.

[31] Cakmak, S., Dales, R. E., and Vidal, C. B. 2007. "Air Pollution and Mortality in Chile: Susceptibility among the Elderly." Environ Health Perspect 115 (4): 524-7.

[32] O’Neill, M. S., Loomis, D., and Borja-Aburto, V. H. 2004. "Ozone, Area Social Conditions, and Mortality in Mexico City." Environ Res. 94 (3): 234-42.

[33] ZHANG, Y., HUANG, W., London, S. J., SONG, G., CHEN, G., and JIANG, L., et al. 2006. "Ozone and Daily Mortality in Shanghai, China." Environ Health Perspect 114 (8): 1227-32.

[34] Bell, M. L., McDermott, A., Zeger, S. L., Samet, J. M., 


\section{Suburban Zones in Madrid (Spain)}

and Dominici, F. 2004. "Ozone and Short-Term Mortality in 95 US Urban Communities, 1987-2000.” JAMA 292 (19): 2372-8.

[35] KAN, H., London, S. J., CHEN, G., ZHANG, Y., SONG, G., ZHAO, N., et al. 2008. "Season, Sex, Age, and Education as Modifiers of the Effects of Outdoor Air Pollution on Daily Mortality in Shanghai, China: The Public Health and Air Pollution in Asia (PAPA) Study." Environ Health Perspect 116 (9): 1183-8.
[36] Katsouyanni, K., Samet, J. M., Anderson, H. R., Atkinson, R., L., Tertre, A., and Medina, S., et al. 2009. "Air Pollution and Health: a European and North American Approach (APHENA)." Res Rep Health Eff Inst. 142: 5-90.

[37] Madrid Community Institute of Statistics. "Industrial Atlas of the Madrid Community." Accessed May 31, 2017. http://www.madrid.org/iestadis/fijas/estructu/general/terri torio/descarga/atlasindustria07.pdf. 